\title{
TIPOS DE LECTURA, TIPOS DE TEXTO
}

Carlos Pereda

INSTTTUTO DE INVESTIGACIONES FILOSÓFICAS

Universidad Nacional Autónoma de MÉxico

Pocas actividades se nos han vuelto tan decisivas como la lectura, pocas también tan silenciosamente riesgosas y, por ello mismo, presa fácil de vértigos. Se protestará: habiendo tantas dificultades teóricas y prácticas es tonto fantasearlas donde no las hay. ¿Por qué fingir abismos en una actividad inocente como la lectura? Por ejemplo, he aquí un conjunto variado de textos ino se agota el fenómeno de leer en el proceso de acceder a ciertos sentidos y, en algunos casos, quizá en la mayoría de los casos, también, y sobre todo, a ciertos referentes? Quien responda con la afirmativa tal vez precisará: si en la actividad de leer se corre peligros, ellos se originan en el contenido del texto por leerse; es decir, la lectura es siempre la misma y, si hay peligro, éste se vincula con los sentidos y referentes por aprehender. Llamaré a esta posición “determinismo hermenéutico". La caracterizo grosso modo con dos postulados. Primer postulado: la lectura es un fenómeno simple y uniforme; segundo postulado: la lectura es una actividad por entero dependiente del texto que se lee.

Por lo pronto, tengo dos sospechas con respecto a esta posición. Primero, seguramente se trata de una caricatura; sin embargo, espero que como en cualquier buena caricatura, no se inventa, sólo se exageran tendencias que están presentes en maneras de pensar en apariencia más compartibles; si estoy en lo cierto, entonces, muchos que en principio no estarán dispuestos a defender abiertamente estos postulados, si se los presionara y fueran consistentes, deberían terminar abrazándolos. Segundo, quienes, de uno u otro modo, asuman esta posición sucumben en el vértigo objetivista en relación con los textos. Pero ¿todo ello es verdad? ¿Conforma el determinismo hermenéutico una posición tan fácil de atacar?

Empiezo por reconstruir una tipología de lecturas (1); ésta lleva a plantearnos una alternativa radical, pero simétrica al determinismo: el cindeterminismo hermenéutico" (2). Se buscará entonces una tipología de textos (3); con base en el debate sobre las relaciones entre ambas tipologías, rechazaré tanto el determinismo como el indeterminismo hermenéutico (4). 
En primer lugar, opongamos dos actitudes básicas de cualquier lector: las "lecturas informativas" y las "lecturas apropiadoras". En una lectura informativa, a quien lee no le interesa para nada detenerse en el texto que lee, sino que procura encontrar de inmediato los referentes de ese texto, por ejemplo, si se planea un paseo y se consulta en el diario el informe meteorológico, el interés de tal lectura consistirá en enterarse de cuál será mañana el estado del tiempo y, probablemente, casi nadie en esa situación se demorará en repasar cómo está redactado el informe. La lectura informativa tiende a borrar al texto en pos de su referencia, aunque nunca lo borre totalmente: así como hay "condiciones normales de percepción", hay también "condiciones normales de lectura" y el lector de una lectura informativa tiene que juzgar, al menos, si se encuentra en tales condiciones. Nada de ello sucede en una lectura apropiadora. En ésta no sólo interesa acceder a los referentes -cuando ello todavía interesasino, ante todo, atender al texto mismo e indagar cómo el texto se aproxima a sus sentidos y a sus referentes, o por qué y para qué lo hace; en la lectura apropiadora se confronta al texto con el propio discurso del lector para que éste rescate elementos que le sean, en algún aspecto, valiosos. Desde la lectura apropiadora se toma al texto que ha de leerse como materia prima que debe elaborarse: el texto se convierte en un candidato a ser alimentado, y directamente, la propia voz.

En segundo lugar, podemos distinguir las lecturas apropiadoras en "explicativas", "argumentadas" e "itinerantes". En una lectura explicativa el texto es una herramienta para reconstruir y hacer inteligibles fragmentos del pasado o del presente, esto es, volvemos al texto parte de un "banco de datos"; en tal lectura, elucidamos cómo, por qué y para qué el texto dice lo que dice. Así, un historiador de la Nueva España podrá recoger, entre otros documentos, la Respuesta a Sor Filotea de la Cruz de Sor Juana y usar la lectura de este texto como un material más en la explicación de ciertos conflictos entre diversos poderes hacia finales del siglo XVII en México.

Una lectura argumentada tiene una relación más directa con el texto. En tal lectura lo que interesa es discutir: una lectura argumentada se constituye al producirse un debate entre texto y lector; el debate se genera a partir de preguntas directas como: ¿de qué manera hay que comprender lo que dice el texto?, ¿es verdad lo que afirma?, ¿qué relevancia tiene? La primera pregunta con frecuencia llevará a reconstruir un texto "quitándole la paja" para hacer más visibles sus estructuras argumentales: he aquí una premisa, he aquí otra, he aquí la conclusión. . L La segunda pregunta pide examinar la corrección de los argumentos y los respaldos externos a cada una de las premisas; a partir de la tercera pregunta se planteará la pertinencia y el valor de los argumentos en relación con los problemas que éstos buscan iratar. 
Se atacará: las preguntas de comprensión, verdad y relevancia no pertenecen en exclusiva a la lectura argumentada, sino a varios tipos de lectura, tal vez a toda lectura. ¿Acaso las tres preguntas no son pertinentes a la lectura informativa? Sin duda, en medio de tal lectura, un lector podría introducir estas preguntas, pero apenas lo haga, deja de leer informativamente y convierte esa lectura en lectura argumentada. ¿Y la lectura explicativa?

Pienso que explicar es una forma de argumentar (aunque puede discreparse al respecto); sin embargo, hay que distinguir entre las argumentaciones directas o argumentaciones propiamente dichas y las argumentaciones oblicuas o explicaciones. Si no me equivoco, sólo en las argumentaciones propiamente dichas las preguntas de comprensión, verdad y relevancia funcionan directamente, en las explicaciones lo hacen de manera oblicua.

Supongamos que un historiador indaga los Pensamientos de Pascal en tanto documento de los conflictos entre el Estado, la Iglesia y el movimiento jansenista en la Francia del siglo XVII. Ese historiador, sin duda, tendrá que comprender de qué tratan esos textos o comprender directo, pero este momento de lectura informativa no conformará más que una "circunstancia de pasaje", nuestro historiador también tendrá que comprender cómo fueron comprendidas esas ideas por sus contemporáneos o comprender oblicuo, siendo el primer comprender sólo un medio del segundo, pues todo comprender oblicuo se prolongará en una explicación: cómo funcionaron socialmente esas ideas, esto es, de qué realidad social fueron causas y efectos. A su vez, para un historiador en tanto tal no habrá preguntas directas de verdad, el historiador qua historiador no se pregunta si tal o cual idea de Pascal es verdadera; tampoco, y en el mismo sentido, habrá preguntas directas de relevancia. Las preguntas de verdad y relevancia en una lectura explicativa son sólo oblicuas: no atañen la verdad y relevancia de las ideas de Pascal, sino la verdad y relevancia, en este caso, de la explicación social que se ha ofrecido de ellas.

Dicho de otra manera: el lector de una lectura explicativa es una tercera persona que recoge el texto que ha de leerse como un material que debe ser explicado o formar parte de una explicación. En cambio, el lector de la lectura argumentada es una primera persona que entabla un debate con el texto.

También el lector de una lectura itinerante es un lector en primera persona. No obstante, la lectura itinerante es radicalmente diferente de las otras lecturas apropiadoras: enfatiza, casi diría, escenifica el punto de vista de la subjetividad. El texto de una lectura itinerante se convierte, una y otra vez, en punto de partida para un viaje... de la imaginación, de la memoria, de la capacidad de soñar. Precisamente, es en relación con estos "viajes" que debemos plantear las preguntas de comprensión, verdad y relevancia de una lectura itinerante; por eso, se trata también de preguntar a partir de, a partir de preguntas oblicuas, aunque en sentido diferente al que tienen las preguntas de una lectura explicativa: en un caso, son oblicuas, porque tales preguntas no aluden a lo 
que el texto afirma, sino a la explicación que se produce a partir del texto, en el otro, se trata de preguntas oblicuas porque en el texto no hay genuinas aseveraciones, sino que es la lectura la que tiene que encontrarlas a partir de los itinerarios que recorre. Quien lea, por ejemplo, estas líneas de Quevedo:

Miré los muros de la patria mía

si a un tiempo fueron, ya desmoronados...

acaso piense en la tierra y en la vida de Quevedo, pero también podría recordar o imaginar otras tierras asoladas, otras vidas hechas trizas... y, casi inevitablemente, acabará sintiendo su propia tierra, sobre todo, su propia vida... y en este flujo y reflujo de los pensamientos, las imágenes, los recuerdos, los sentimientos,... se producirán diferentes aseveraciones. Además, este flujo y reflujo no tiene más límite que el que le imponga la propia lectura. Pero ninguna lectura apropiadora tiene otra clase de límites... ¿Por qué?

Hasta el momento había dejado de lado las relaciones entre lectura y relectura. Quien se demore en estas relaciones y tenga en cuenta el contraste entre lectura informativa y apropiadora, casi inevitablemente tenderá a pensar que las palabras "releer", "relectura" refieren en ambos casos a actividades diferentes, más todavía éno hay incluso razones para reservar la palabra "releer" en relación con el releer apropiador y aludir al "releer informativo" con la expresión "repetir una lectura"? ¿De qué hablo?

El leer informativo consiste en un acto delimitado por el contenido del texto que debe leerse: apenas se capta la información que el texto ofrece, acaba el acto de la lectura. De ahí que el "releer informativo" se configure con una o varias repeticiones: se vuelve a hacer el mismo acto de la misma manera pues no se lo había logrado llevar a término satisfactorio, a saber, se fracasó en el objetivo de enterarse de la información buscada. El releer informativo es un acto parasitario del leer informativo y, desde el punto de vista teórico, superfluo. No así el releer apropiador. En relación con las lecturas explicativas, argumentadas e itinerantes, releer, lejos de ser una actividad teóricamente superflua, es constitutiva de tales lecturas. Porque, en sentido estricto, no existe ningún leer apropiador: en una lectura apropiadora, la primera lectura es siempre el comienzo de una serie... No olvidemos que en todo leer explicativo, argumentado o itinerante habrá necesariamente intervenciones muy claras del lector - rearticulando, preguntando, reconstruyendo, discutiendo, soñando...-; esas intervenciones se sedimentan y conforman procesos que cada nueva relectura hace crecer, reorganiza, complica. Por eso, cualquier leer apropiador conoce sólo límites internos y provisorios (los límites de cierto proceso, nunca concluido, de relectura): por eso, ninguna lectura apropiadora tiene otros límites que los que ella misma encuentra.

Pero fijemos ya las distinciones introducidas en un cuadro: 


\begin{tabular}{|l|l|}
\hline $\begin{array}{l}\text { Lecturas } \\
\text { informativas }\end{array}$ & $\begin{array}{l}\text { Lecturas } \\
\text { apropiadoras }\end{array}$ \\
\hline \multirow{7}{*}{} & $\begin{array}{l}\text { En tercera persona: } \\
\text { argumentadas oblicuas } \\
\text { o explicativas }\end{array}$ \\
\cline { 2 - 2 } & $\begin{array}{l}\text { En primera persona: } \\
\text { argumentadas directas } \\
\text { o argumentadas } \\
\text { propiamente dichas }\end{array}$ \\
\cline { 2 - 2 } & $\begin{array}{l}\text { En primera persona: } \\
\text { itinerantes }\end{array}$ \\
\hline
\end{tabular}

Cuadro 1: Tipos de lecrura

En el cuadro l se articula una tipología, no una clasificación: las cuatro actitudes indicadas, leer informativo, explicativo, argumentado c itinerante, a menudo no poseen límites precisos y, no pocas veces, un lector suele pasar casi sin darse cuenta de una actitud a la otra, por ejemplo, la lectura de un ensayo suele hacernos oscilar entre la lectura argumentada y la itinerante $y$, en algunas ocasiones, códigos legales y morales del pasado exigen de nosotros una lectura explicativa y, a la vez, argumentada; con frecuencia también, tanto la lectura explicativa como la argumentada no se configuran más que como inevitables prolongaciones de una lectura informativa.

Lo que más importa: quien acepte esta tipología eliminará el primer postulado del determinismo hermenéutico con respecto a la lectura: la lectura no es un fenómeno simple y uniforme sino, por el contrario, una actividad radicalmente variada y con diversos grados de complejidad. Ahora bien, ¿cómo atacar el otro postulado?

El segundo postulado del determinismo hermenéutico establece la completa dependencia de la lectura con respecto al texto: parecería que quien tenga en cuenta la comprobación de que ninguna lectura apropiadora posee más que límites internos, ya posee un buen argumento en su contra. Atendamos, no obstante, la siguiente propuesta, mucho más arriesgada:

Con respecto a cualquier texto puede usarse cualquier tipo de lectura que reubicará al texto leído y lo rearticulará: que lo que constituirá. 
Si se respalda esta propuesta, no sólo se eliminará el segundo postulado sino que más positivamente, se defenderá la tesis de que, lejos de constiruirse la lectura como mero dependiente del texto, la constitución efectiva de cualquier texto depende enteramente de su lectura.

Por lo tanto, quien acepte la tipología fijada en el cuadro 1 y esta propuesta, propone las contradictorias de los postulados del determinismo hermenéutico: la posición del “indeterminismo hermenéutico". Pero ide dónde salen tales contrincantes?

Toda polémica particular se inscribe en (de algún modo actualiza) una o varias polémicas generales. Determinismo hermenéutico o indeterminismo en relación con la lectura y los textos son, inmediatamente, "aplicaciones" $o$, si se prefiere, ecos de posiciones en torno al lenguaje. El determinismo hermenéutico pensará al lenguaje como un sistema de reglas innatas, o de convenciones sociales, tan férreamente articulado que en condiciones habituales produce mensajes claros y más o menos precisos. Por el contrario, para el indeterminismo nada tienen que hacer en una investigación sobre el lenguaje expresiones como "sistema", "reglas innatas", "articulaciones férreas" $\mathrm{e}$ incluso, tal vez, "convenciones sociales"; el lenguaje - si todavía se quiere usar esa palabra "demasiado totalizadora" - no es más que un conjunto muy variado de prácticas que, a menudo, tienen muy poco en común las unas con las otras... Pero no quiero dejarme distraer por esta polémica general; regreso a la lectura y a los textos. Para quien defienda un indeterminismo hermenéutico en relación con ellos, leer y releer pierden su calmosa seguridad al abrigo del texto, incluso ya ni siquiera parece haber riesgos del texto, sino, únicamente, riesgos del lector. Sin embargo, adoptando este indeterminismo ino se está corrigiendo un error con otro? ¿No sucumbe el indeterminista al vértigo ontológico simétricamente opuesto a aquel en que caía el determinista? Si éste objetiviza "por completo" el texto ‘acaso el indeterminista no lo subjetiviza igualmente "por completo"?

Es probable que desde varias posiciones se tienda a admitir que una tipología de lecturas no es indiferente a una tipología de textos, esto es, que hay algo así como correlaciones sistemáticas entre algunos tipos de lecturas y algunos tipos de texto. Atendamos dos de esas expresiones. Por lo pronto, hay que enfatizar que la expresión " $X$ no es indiferente de $\Upsilon$ " no implica ni " $X$ es totalmente dependiente de $Y$ ", esto es, " $X$ es en todos sus aspectos dependiente de $Y$ ", ni tampoco " $X$ es totalmente independiente de $\Upsilon$ ". Por otra parte, la expresión "correlaciones sistemáticas" se usa en el sentido de: los vínculos entre los tipos de lectura y los tipos de texto no son casuales; entre otros vínculos, hay que tener presente que la producción de cada tipo de texto se lleva a cabo desde la 
anticipación de que, en relación con ciertos textos, se ejercerá ('siempre o habitualmente?) cierta lectura. Recuérdese: espontáneamente leemos cada texto de una manera, esto es, los textos parecen pre-condicionar o incluso programar sus lecturas. Pero ies este el caso? Examinemos la siguiente tipología de textos.

Correlatos sistemáticos de una lectura informativa son, como se indicó, fragmentos importantes de un diario y, también, de un manual científico, una carta o un telegrama, un libro de cocina o una guía de teléfonos. Se trata de textos transparentes: el lector atiende a la referencia apuntada por las palabras, desentendiéndose de éstas. Textos transparentes son, por así decirlo, textos notextos, textos sin interés textual. Un manual de ciencias es un instrumento que se usa para obtener algunos saberes y, una vez adquiridos, se deja de lado. En una biblioteca personal no suelen guardarse manuales científicos; atravesada la fase de aprendizaje a la cual se dirige el manual, solemos regalarlo a quien lo necesite, tal vez lo arrumbamos, o incluso lo desechamos, como se elimina un artefacto ya inservible. El tiempo de valor de uso de un texto no-texto, de un texto transparente es, relativamente, preciso: como su única función es transmitir informaciones, el texto envejecerá tan rápido como envejezcan, 0 incluso dejen de tener sentido (como en el caso del telegrama y de la guía de teléfonos), sus informaciones. En tanto lectura predominante referencial, la lectura informativa conforma un leer confiado: el lector va a donde lo lleva el texto, se deja llevar por él sin mayores resistencias, también sin demasiadas iniciativas, sin intervenciones enérgicas. El texto tiene algo que informar al lector y el lector procura recibir esa información, y nada más.

Apenas el lector se aleja un poco del texto y recobra su propia voz, esto es, apenas el lector aparece como un personaje importante en la escena de la lectura, la lectura informativa comienza a dejar paso a las lecturas apropiadoras. La lectura informativa es una herramienta; las lecturas apropiadoras son más, algo así como la construcción de un experimento que el lector hace con el texto. Como señala el cuadro 1, se dispone de varios tipos de lecturas apropiadoras, por tanto, seguramente existen también varios tipos correlativos de textos no transparentes u opacos: de textos con interés textual.

Para un investigador en ciencias sociales, desde el historiador hasta el psicólogo, los textos que recoge como estofa de su trabajo se convertirán de inmediato para él en protocolos retóricos, psicológicos o históricos. Sin embargo, obsérvese que a diferencia de otros textos, lo que podemos llamar textos "protocolares" son, en tanto tales, una construcción, desde cierto interés teórico, del investigador. Por ejemplo, al historiador que lea qua historiador una correspondencia del siglo XIX, con frecuencia - tal vez en la mayoría de los casos- no le interesarán las informaciones cuya intensión de transmitir generó esas cartas, sino que, según la investigación que lleve a cabo -esto es, 
según su interés historiográfico- construirá con base en tales cartas artefactos retóricos pertenecientes a una tradición, testimonios de una psicología o documentos de cierta sociedad.

A su vez, quien lea un texto cuya intensión explícita sea convencer en torno a uno o varios problemas, articulando uno o varios argumentos, desde la editorial más distraida en el diario del día hasta la Critica de la razón pura, si lee esos párrafos en tanto argumentos, no tendrá otra opción que olvidarse un poco del texto y repensar los argumentos por su propia cuenta, lo que incluye argumentar a su favor o en su contra. Por su parte, los correlatos sistemáticos de las lecturas itinerantes los encontramos en los productos de esa institución anómala, la literatura. Los textos literarios, en cualquiera de sus eventuales géneros, o mezclas de géneros, o transgresión de géneros. .., exigen del lector actividades un tanto raras, desde cierta complicidad elemental al leer una novela, hasta un tiempo de lectura altamente diferenciado para releer poesía (una poesía tiene que ser muy mala para que meramente se la lea). Estos últimos textos, los poemas, ofrecen el ejemplo más característico, más extremo, de texto literario. Entre otras propiedades, los textos de la poesía son los únicos que se suelen auto-clasificar como tales: los otros textos pertenecen a la indiferenciada prosa, la poesía se constituye, al menos originariamente, en verso. Frente a un poema la atención se detiene: a menudo unas pocas líneas en medio de una página en blanco, con palabras rimadas, no pocas veces violando las reglas más conocidas del lenguaje... ¿Qué es esto? Por lo menos, queda claro de lo que no se trata: no se procura, ante todo, ni entregar nueva información, ni el testimonio de una psicología, ni un documento social, ni un argumento (aunque, de manera indirecta, los textos de la poesía pueden incluir esos elementos). Pero, ícómo describir esos textos más positivamente? Acaso, entre otras caracterizaciones, se podría también decir que estamos ante materiales que deben usarse en complejas ceremonias: el lector parte del texto y explora, en parte por cuenta suya, ciertos territorios de la memoria, del deseo, de la imaginación..., para volver, una y otra vez, a releer el texto y, también, para de nuevo volver a partir de él. Un gran texto literario y un atento lector pueden hacer de este ir y venir, de este proceso de relecturas, un movimiento infinito.

Fijemos en otro cuadro los tipos de texto que hemos correlacionado sistemáticamente con los tipos de lectura del cuadro 1 (véase Cuadro 2).

La discusión que nos llevó a la tipología del cuadro 2, en lo que respecta al segundo postulado, parece no darle la razón ni al determinista hermenéutico ni al indeterminista.

En contra del determinista se han acumulado ya datos que presentan, al menos a cualquier lectura apropiadora, como una lectura activa, en ningún caso "por completo" dependiente del texto que lee. 


\begin{tabular}{|l|l|}
\hline Textos transparentes & Textos opacos \\
\hline \multirow{4}{*}{} & Protocolares \\
\cline { 2 - 2 } & Argumentales \\
\cline { 2 - 2 } & Literarios \\
\hline
\end{tabular}

Cuadro 2: Tipos de texto

Por otra parte, también hay que rechazar las pretensiones del indeterminista: no se puede leer cualquier texto con cualquier tipo de lectura. Repasemos esta afirmación caso por caso.

Procurar leer textos opacos con una lectura informativa es probable que nos enrede en confusiones o en imposibles. Si un lector mexicano de 1989 leyese con lectura informativa una carta de 1689 dirigida a un conde de Madrid casi es seguro que se confundiría; en una confusión más grave todavía se encontrará quien lea un cuento con la misma lectura informativa que se usaría con las noticias policiales del diario del día. Por lo demás, nadie puede siquiera intentar leer a Góngora o a Hegel con lectura informativa.

Indaguemos en la dirección inversa: ise puede leer cualquier texto con cualquier lectura apropiadora?

Por lo menos, es posible leer cualquier texto con lectura explicativa: todo texto puede convertirse en artefacto retórico, testimonio psicológico o documento social (o parte de un testimonio psicológico o de un documento social).

Menos fácil es el caso de la lectura argumentada. ¿En qué consistiría una lectura argumentada (no explicativa) de la lista de huéspedes de un hotel? Por otra parte, la lectura argumentada tampoco se confina a los textos explícitamente argumentales, por ejemplo, muchos textos literarios suelen leerse con lectura argumentada éentonces... ? Tal vez la siguiente distinción ayude a discutir el caso de los posibles correlatos de una lectura argumentada.

Distingamos entre textos "argumentales actuales" o textos en los que el propósito inmediato es articular una argumentación y textos "argumentales virtuales" o textos en los que se puede reconstruir una argumentación, aunque ésta no conforma ningún propósito inmediato del texto. Textos filosóficos, científicos o ensayos de opinión suelen ser ejemplos característicos de textos argumentales actuales, mientras que relatos, novelas, obras de teatro, poemas, noticias, cartas... en los que de un modo u otro se argumenta o se pueden reconstruir argumentos lo son de textos argumentales virtuales. Entonces ya podemos indicar: sólo los textos argumentales, actuales o virtuales, pueden ser el objeto de una lectura argumentada. 
En cuanto a la lectura itinerante, ¿ puede leerse cualquier texto con tal lectura? La respuesta afirmativa es una de las lecciones de las llamadas "vanguardias" de este atiborrado siglo XX. Así, no es difícil encontrar informaciones del diario, incluso tan triviales como la lista de huéspedes de un hotel, en medio de un libro de poemas y funcionando en tanto poesía (por ejemplo, en Peter Handke). No obstante, la afirmación "cualquier texto puede leerse con lectura itinerante" suele confundir si, de inmediato, no se le agrega "en ciertas condiciones". Pero, ¿en cuáles?

Por lo pronto, distingamos entre una lectura itinerante primaria o lectura itinerante de textos literarios y una lectura itinerante secundaria o lectura itinerante de otros textos. Sospecho que sólo es posible una lectura itinerante de otros textos si ya hemos aprendido a leer de manera itinerante ejercitándonos en lecturas itinerantes primarias. Esto es, la lectura itinerante de cualquier texto sólo es posible en ciertas condiciones, entre otras, tal lector debe pertenecer a una tradición en la que existe algo así como la institución "literatura" y, además, en esa tradición ocupan un lugar importante en la vida de sus participantes, las lecturas itinerantes primarias. Quiero decir: cualquier lectura itinerante secundaria es enfáticamente parasitaria de las lecturas itinerantes primarias, constituyendo necesariamente éstas la "normalidad" y aquéllas las "anomalías".

Poco a poco ha cobrado mayor fuerza la sospecha de que, en relación con los textos y las lecturas, tanto el determinismo hermenéutico como el indeterminismo están equivocados. Como suele pasar cada vez que se indagan los vínculos entre sujeto y objeto, o entre ciertos tipos de sujeto y ciertos tipos de objeto --la vieja polémica entre realismo y anti-realismo en que tampoco quiero distraerme, aunque, como toda polémica general, inevitablemente echará su sombra, o su luz, sobre este debate particular - ambos, determinismo hermenéutico o indeterminismo, sucumben en vértigos ontológicos: el determinismo, en pleno vértigo objetivista, convierte a los textos en superhechos y desustancializa a la lectura, casi hasta borrarla; el indeterminismo, en pleno vértigo subjetivista, erige como única norma de las relaciones entre texto y lectura al "todo vale" del lector y así, vuelve irreales los textos (y ésto, paradójicamente, no pocas veces aduciendo su "respeto infinito" por ellos). Si no me equivoco tenemos, pues, que abandonar ambas posiciones y su mutua complicidad. Reitero algunos lineamientos de mi propuesta:

Hay varios tipos de lectura y relectura y varios tipos de texto. Ni la lectura es una actividad "por completo" dependiente del texto, ni éste se reduce a sus eventuales lecturas. A partir de las correlaciones sistemáticas insti- 
tacionalmente establecidas entre ciertos tipos de texto y ciertos tipos de lectura, hay que afirmar, por un lado, que sólo los textos transparentes pueden leerse con lectura informativa, por otro lado, respecto a cualquier texto puede apelarse a la lectura explicativa y, en ciertas condiciones, a la lectura itinerante y, además, sobre textos actualmente argumentales, la lectura argumentada podrá ejercerse también sobre textos que ella pueda reconstruir como argumentales de manera virtual.

Ataque: se han reconstruido dos posiciones tan extremas, determinismo e indeterminismo hermenéutico, que a partir de esas caricaturas no ha sido difícil razonar una posición intermedia.

Defensa: tales "caricaturas" contienen postulados más o menos implícitos en la mayoría de las posiciones en discusión. Pero incluso si éste no fuera el caso, valdría igualmente la pena atacar tanto al determinismo como al indeterminismo hermenéutico en tanto tentadoras posibilidades de los vértigos ontológicos en relación con las lecturas y los textos.

Ataque: la propuesta defendida no constituye ninguna "posición intermedia", no conforma ninguna opción genuina ni para el determinismo ni para el indeterminismo; más bien, lo que se introduce es un sincretismo sin ton ni son de ambos. ¿Acaso no se propone, o al menos se sugiere, que los ejemplos de lectura informativa hay que explicarlos a partir del determinismo, mientras que los ejemplos de lectura apropiadora hay que explicarlos a partir del indeterminismo? De esta manera, se prepara una mezcla que sólo puede encubrir su inconsistencia con confusión.

Defensa: no es verdad que se procure explicar unos ejemplos por una posición y otros, por otra y, luego, mezclarlo todo. Lo que se afirma es, por un lado, que ninguna de las dos posiciones, puede siquiera tomar en cuenta los ejemplos que no le son favorables -el determinista no quiere saber nada de las lecturas apropiadoras, ni el indeterminista de la lectura informativa-y, por otro, que ambas posiciones explican mal incluso los ejemplos que le son favorables.

Esta última afirmación tal vez sorprenda: ¿en qué sentido el determinismo falla en relación con la lectura informativa? En primer lugar, no se es capaz de tener en cuenta que la lectura informativa conforma un tipo de lectura entre otras. En segundo lugar, el lector de una lectura informativa tiene que juzgar, al menos, si se encuentra en condiciones normales de lectura informativa; así, en relación con nuestro ejemplo de leer en el diario el informe meteorológico porque se planea un paseo, el lector tendrá que tener en cuenta entre otras condiciones normales de creencia, si el diario es lo suficientemente serio como para poder confiar en sus informaciones y con cuánta exactitud el informe meteorológico puede predecir el tiempo, lo que impide que incluso la lectura más distraida sea una actividad "por completo" dependiente del texto. A su vez, también el indeterminista falla en relación con las lecturas apropiadoras 
al convertir tales lecturas en proyecciones del lector, ignorando los vínculos entre lectura y texto, y las resistencias que todo texto impone en tales vínculos.

No se busca, pues, mezclar posiciones, sino rescatar la verdad que cada una de las posiciones exagera hasta transformarla en fetiche: la objetividad del texto en el determinismo, la actividad del lector en el indeterminismo. Con más modestia, particularizando, en la nueva propuesta se comienzan a reestablecer los entreverados vínculos entre lectura y texto. También, la realidad y la movilidad de ambos: la producción textual se lleva a cabo a partir de intensiones que, institucionalmente, anticipan y programan un tipo de lectura; pero un lector no tiene necesariamente que aceptar esas anticipaciones: con frecuencia puede rehusarse a ellas y llevar a cabo otro tipo de lectura o relectura pero, ya sabemos, no cualquier tipo es pertinente o incluso posible. Por otra parte, afirmar que los textos no poseen el régimen de objetividad de los neutrinos, y ni siquiera de los ríos o de los astros, no implica defender que los textos se disuelven en la multiplicidad de sus eventuales lecturas: por decirlo así, el ser de un texto no se reduce a ser leído. A su vez, las lecturas o relecturas, si bien no conforman la tabula rasa que pasivamente recibe las impresiones del texto todopoderoso, tampoco son, ellas mismas, todopoderosas. El atributo "todopoderoso" pertenece al concepto de Dios, reconocer que tal atributo no le conviene ni a la lectura ni al texto —como, por lo demás, a ningún sujeto que sea persona, ni a ningún objeto que se las tenga que ver con esta clase de sujeto- devuelve a ambos su elaborado riesgo: hace lugar al juicio. 